\title{
Biliș ve Kültür Kavramının Mimari Tasarım Üzerindeki Etkileri
}

\author{
Öğr. Gör. Gamze Akbaş ${ }^{1 *}$ \\ Dr. Öğr. Üyesi Arzu Ercetin ${ }^{2}$ \\ Dr. Öğr. Üyesi Vehbi Tosun
}

Geliş tarihi: 21.11 .2019

Kabul tarihi: 08.12.2019

\section{Atıf bilgisi:}

IBAD Sosyal Bilimler Dergisi

Sayı: 5 Sayfa: $615-627$

Yıl: 2019 Dönem: Güz

This article was checked by Turnitin. Similarity Index 5\%

1 İstanbul Kültür Üniversitesi, Türkiye, g.akbas@iku.edu.tr,

ORCID ID 0000-0002-5826-3423

2 İstanbul Kültür Üniversitesi, Türkiye, a.eceoglu@iku.edu.tr,

ORCID ID 0000-0002-8381-0011

${ }^{3}$ İstanbul Kültür Üniversitesi, Türkiye, v.tosun@iku.edu.tr,

ORCID ID 0000-0001-9091-740X

* Sorumlu yazar öz

Zihnin bilimsel çerçevede incelenmesi olarak tanımlanan "bilişsel psikoloji"; mimarlık, eğitim, psikoloji gibi birçok disiplin tarafindan ele alınan bir çalışma alanıdır. Mimarlık alanında, zihin işleyişinin tasarım ve yaratıcılık üzerindeki etkilerini anlayabilmek için, kişisel ve kültürel bilgilerle gelişen "biliş" kavramının üzerinde durulması gerekmektedir. Bir toplumun zihinlerinde depoladıkları bilgiler süreç içinde imgeler, kelimeler, fikirler ve tepkiler şeklinde temsil edilmektedir. $\mathrm{Bu}$ durum, bir topluma ait davranış ilkelerini yansıtan kültürel bileşenleri oluşturmaktadır. Dolayısıyla, mimari yaratıcılıkta bilişsel psikolojinin etkisi ile kültür ve biliş ilişkisi önemli bir yer tutmaktadır. Bu çalışmada, "biliş", "kültürr" ve "mimari tasarım" alanlarını ele alırken, yaratıcılığın bilişsel olarak nasıl çalıştığı üzerinde durulmaktadır. Bu bağlamda, mimari tasarımdaki bilişsel etkiler sırasıyla bilgi depolama şekilleri, bilişsel şemalar, kültür kavramı, kültürel kodlar ve kültürel şemalar kapsamında tartışılmaktadır.

Anahtar Kelimeler: Bilişsel Psikoloji, Biliş, Kültür, Şema, Mimarlık 


\section{The Impacts of Cognition and Culture on Architectural Design}

\author{
Lec. Gamze Akbaş ${ }^{1 *}$ \\ Assist. Prof. Dr. Arzu Erçetin ${ }^{2}$ \\ Assist. Prof. Dr. Vehbi Tosun ${ }^{3}$
}

First received: 21.11 .2019

Accepted: 08.12.2019

\section{Citation:}

IBAD Journal of Social Sciences

Issue: $5 \quad$ Pages: 615-627

Year: $2019 \quad$ Session: Fall

This article was checked by Turnitin. Similarity Index 5\%

1 Istanbul Kultur Universitiy, Turkey, g.akbas@iku.edu.tr,

ORCID ID 0000-0002-5826-3423

2 Istanbul Kultur Universitiy, Turkey, a.eceoglu@iku.edu.tr,

ORCID ID 0000-0002-8381-0011

3 Istanbul Kultur Universitiy, Turkey, v.tosun@iku.edu.tr,

ORCID ID 0000-0001-9091-740X

* Corresponding Author

\begin{abstract}
"Cognitive psychology" which can be defined as the scientific examination of the mind, has been handled by many disciplines such as architecture, city planning, education and psychology. In the field of architecture, in order to understand the effects of mental functioning on design and creativity, it is necessary to focus on the concept of cognition which develops with personal and cultural knowledge. The information stored in the minds of a society is often represented as images, words, ideas, and reactions. This also constitutes cultural components that reflect the principles of behavior that are specific to a society. Therefore, the influence of "cognitive psychology" and the relationship between "culture" and "cognition" play an important role in architectural creativity and design, as well as how one can understand the relationship between man and environment. In this study, while dealing with the fields of "cognition", "culture" and "architectural design" it is emphasized how creativity works cognitively. In this context, cognitive influences in architectural design are discussed in the context of information storage types, cognitive schemes, the concept of culture, cultural codes and cultural schemes, respectively.
\end{abstract}

Keywords: Cognitive Psychology, Cognition, Culture, Schema, Architecture 


\section{GÍRIŞ}

Bilişsel psikoloji mimari tasarım süreci bağlamında ele alındığında, kültürel davranış pratikleri ve zihinsel gösterimlerden (imgeler) faydalanarak bir problemin çözümlenmesini sağlamaktadır. Bir tasarımın yapılandırılması belirli bir problem çözme döngüsünü beraberinde getirmektedir; dolayısıyla, bir problemin zihinde tasarlanması bilişsel tasarım sürecini etkileyen önemli bir faktördür (Goldstein, 2013, s. 559). Bu aşamada ise bellek, imgeleme ve problem çözme gibi etmenler, bireyin tasarlama eyleminde etkili olmaktadır.

Konuya ilişkin olarak, 1970'lerde bilişsel araştırmaların yön verdiği çalışmaların yerini, 1980 ve 90'larda sosyokültürel eğilimler almıştır (McVee, Dunsmore, \& Gavelek, 2005, s. 531). Bu süreçte, biliş ve kültür ilişkisi bilişsel psikolojinin tarihinde önemli bir yer tutmakla birlikte, kültürel kodlar ve kültürel şemalar gibi adlandırmalar bu çalışma alanının alt başlıklarını oluşturmaya başlamıştır. Kültürel kodlar, belli bir coğrafyada birikmiş yaşam bilgisi, imgeler, kavramlar, fikirler ve tepkiler şeklinde tanımlanmaktadır. Kültürel şemalar ise, toplum üyeleri tarafından geniş çapta paylaşılan zihinsel temsillerdir (Sperber, 1996, s. 33).

Ketizmen Önal (2011, s. 156), mimari tasarım ve şema arasındaki ilişkinin bilişsel tasarım sürecinin belirlenmesinde etkili olduğunu ifade etmektedir. Toplumun kendine özgü değerlerini barındıran şemalar, kişisel şema ve kültürel şema olmak üzere iki kategoride incelenmektedir. Kişisel şemalar, toplumda başkaları tarafından paylaşılmayan ya da kendine özgü şemalar olarak adlandırılırken, kültürel şemalar, toplumun ortak bilişsel kaynak stokunun bir parçası şeklinde tanımlanmaktadır (Shore, 1996, s. 47).

En temel tanımı ile kültür bileşenleri; kültürel şemalar, çevresel etkileşim (mimarlık, edebiyat, dil) ve davranış ilkelerinden oluşmaktadır. Kültürel şema ve yaratıcılığı bilişsel bir yaklaşımla ele alan Ketizmen Önal (2011, s. 155-156), tasarım sürecini zihinde gerçekleşen bir durum olması sebebiyle düşünme eylemi olarak tanımlamaktadır. Dolayısıyla, zihinsel bir süreç olarak nitelenen tasarım, her toplumun süregelen davranış ve tutumları ile şekillenerek biçim ve üretimi çeşitlendirmektedir.

Zihnin özellikleri bilişsel psikolojinin temel konusu olduğundan dolayı, uyarıcı - zihinsel tepki davranışsal tepki olarak açıklanmaktadır (Goldstein, 2013, s. 36-37). Tüm bu ifadelerden yola çıarak, bilişi bir yöntem olarak ele almak görsel malzemelerin yorumlanarak tasarımda verilmek istenen mesajların çözümlenmesi ile mümkündür. Bu çalışmada, bir yöntem olarak bilişsel psikolojinin mimari tasarımda nasıl kullanıldı̆̆ 1 ele alınmaktadır.

\section{BÍLIŞíN KAPSAM VE TANIMI}

Biliş (cognition), bireysel ve kültürel bilgiler ile gelişir; dolayısıyla, bu durum deneyim ve bilgi yoluyla şekillenen bir davranış halini almaktadır. Biliş, psikoloji, eğitim, felsefe gibi birçok alanda incelenmektedir; ancak, bilişle ilgili yapılan çalışmalar bilişsel bilimin çatısı altında toplanmaktadır. Augustinos ve Walker'a (1995, s. 32) göre, insan bilişini inceleyen bilişsel bilim, dışarıdan gelen uyaranları ve nesneleri nasıl algıladığımızı, anladığımızı, depoladığımızı ve hatırladığımızı inceler ve insan zihninin bu bilişsel süreçlerde nasıl çalıştığını anlamaya çalışır.

Goldstein (2013, s. 33) tarafindan maddeler halinde siralanan zihin kavramı, olay, beceri ve imgeler ile ilgili verilerin korunması, geri çağrılması ve kullanılmasında etkin rol oynamaktadır.

- Alg1: Görme ya da duyma,

- Dikkat: İnsanlarla konuşma,

- Dil: Konuşma sırasında dili anlama ve üretme,

- Bellek: Geçmişte olan bir eylemin hatırlanması,

- İmgeleme: Anımsama ya da zihinde canlandırma,

- Problem Çözme: Alternatifler bulmak ya da çözümler üretmek,

- Bilgi: Verilere ulaşmak veya elde etmek,

- Kararlar: Şartlara göre davranmaktır. 


\section{Biliş: Bilgi Depolama}

Bellek, özgün bilgiler artık bulunmadığında uyarıcı, imge, olay, düşünce ve becerilerle ilgili bilgilerin korunmasında, geri çağırılmasında ve kullanılmasında rol oynayan süreç şeklinde tanımlanmaktadır (Goldstein, 2013, s. 214). Bellekte kodlama, depolama ve geri çağırma olmak üzere üç işlem vardır. Kodlama işlemi, bir uyarıcının zihnindeki tasarımlanma biçimidir (Goldstein, 2013, s. 232).

Depolama işlemi, kodlanan bilgilerin saklanması ve geri çağırma işlemi bellekte saklanan bilgilerin kullanılması şeklinde ifade edilmektedir. Bu noktadan hareketle, zihnin işleyişini kavramlar, şemalar ve senaryolar şeklinde ele alan görüşler ön plana çıkmaktadır (Bruning, Schraw, Norby ve Ronning, 2004, s. 47).

Kavramlar: Belirli bir nesneyi algilamayabilmenin temel yolu, benzerlikler etrafinda toplamak ya da gruplandırmaktır (Bruning, Schraw, Norby ve Ronning, 2004, s. 45). Çünkü kavram; bellek, düşünme, algılama, dili anlama gibi çeşitli bilişsel işlevlerde yakından ilişkilidir. Bu nedenle, varlıklar kategoriler olarak adlandırılan bir işleve sahiptir; aynı zamanda, daha önce deneyimlemediğimiz varlıkları da anlamamıza yardım eder. Bu noktada, kavramlar zihnin temel noktasını oluşturmaktadır. Örneğin, bir ağaç ya da kuş kavramı, zihnimizde çok sayıda benzer örneklerin bir araya gelmesiyle oluşmaktadır.

Şema: Durumlar, olaylar, eylemler ve nesneler ile ilgili bilgileri düzenlemek amaciyla kullanılan şemalar, temel olarak deneyim ve biliş arasındaki ilişkiyi temsil etmektedir (D'Andrade, 1992, s. 28; Bruning, Schraw, Norby ve Ronning, 2004, s. 22-23). Depolanan bilgileri düzenleyen ve kategorize eden şemalar, kavramların bir araya gelerek anlamlı bir bütün oluşturmasıdır. Örneğin, ofis şeması çalışma masası, sandalye, kalem, kâğıt gibi çeşitli nesnelerin bir araya gelmesiyle meydana gelmektedir.

McVee, Dunsmore ve Gavelek (2005, s. 547), şemaları birey ve çevre arasındaki sosyal etkileşimden oluşan sosyo-kültürel yapılar şeklinde açıklamaktadır; bu kapsamda, Vyogotsky kültürel gelişim sürecini "Vyogotsky Space" diyagramı ile ifade etmektedir (Görsel 1). Bu diyagrama göre, bilginin depolanması, sosyal-bireysel (social-individual) ve kamu-özel (public-private) alanlar arasındaki ilişkiyle meydana gelmektedir (McVee, Dunsmore ve Gavelek, 2005, s. 547).

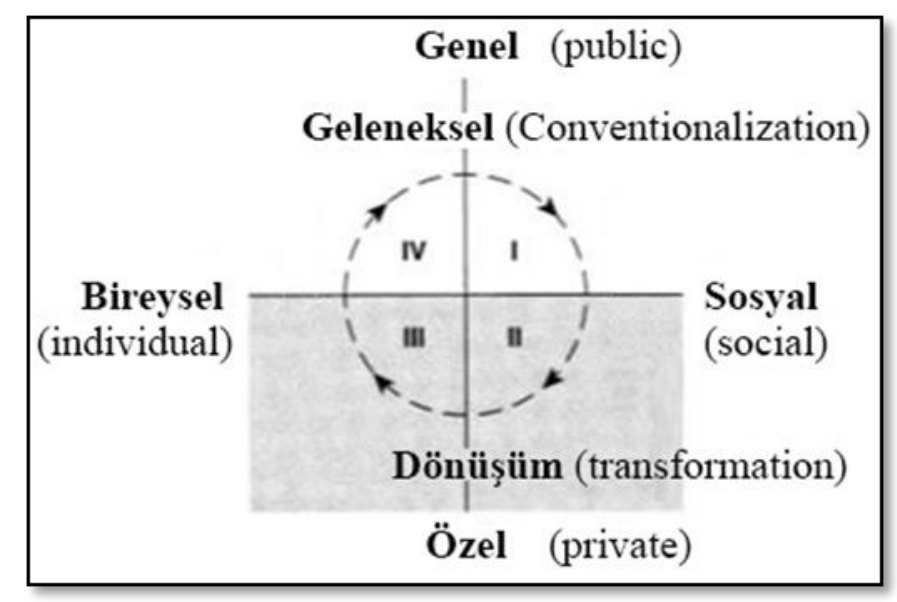

Görsel 1: “Vyogotsky Space” diyagramı (Mc Vee, Dunsmore ve Gavelek, 2005, s. 548)

İnsanlar, yaşamları boyunca sorulara çözüm bulma ihtiyacını hissetmiştir; bu bağlamda, öğrenme ve bilgi edinme durumu diğer canlılardan ayıran en büyük özelliktir. Her bir insan sahip olduğu bireysel bilgi iletişimini de güçlü kılar. Öğrenme isteği ve iletişim kurma becerisi ile oluşan kavramı kültür olarak ifade etmeyi mümkün kılmaktadır. Şemalar ile erişilmek istenen bilgiler sembol ve mesajlar yoluyla ilerleyen sürecin bir göstergesi olarak karşımıza çıkmaktadırlar; çünkü bilgilerin geri çağırılması ve kullanılmasında şemalar pratik ve hızlı çalışmaktadır.

Senaryolar: Bir olayın hafızamızda depolanan bilgiler doğrultusunda şematik olarak gerçekleşmesidir. Senaryolar, günlük yaşamımızda kanıksadığımız durumların merkezini 
oluşturmaktadır (Bower, Black ve Turner, 1979, s. 179). Görsel 2'de de görüldüğg̈ gibi, bir bireyin restorana gitmesi kişisel bir senaryo şeklinde ifade edilebilir.

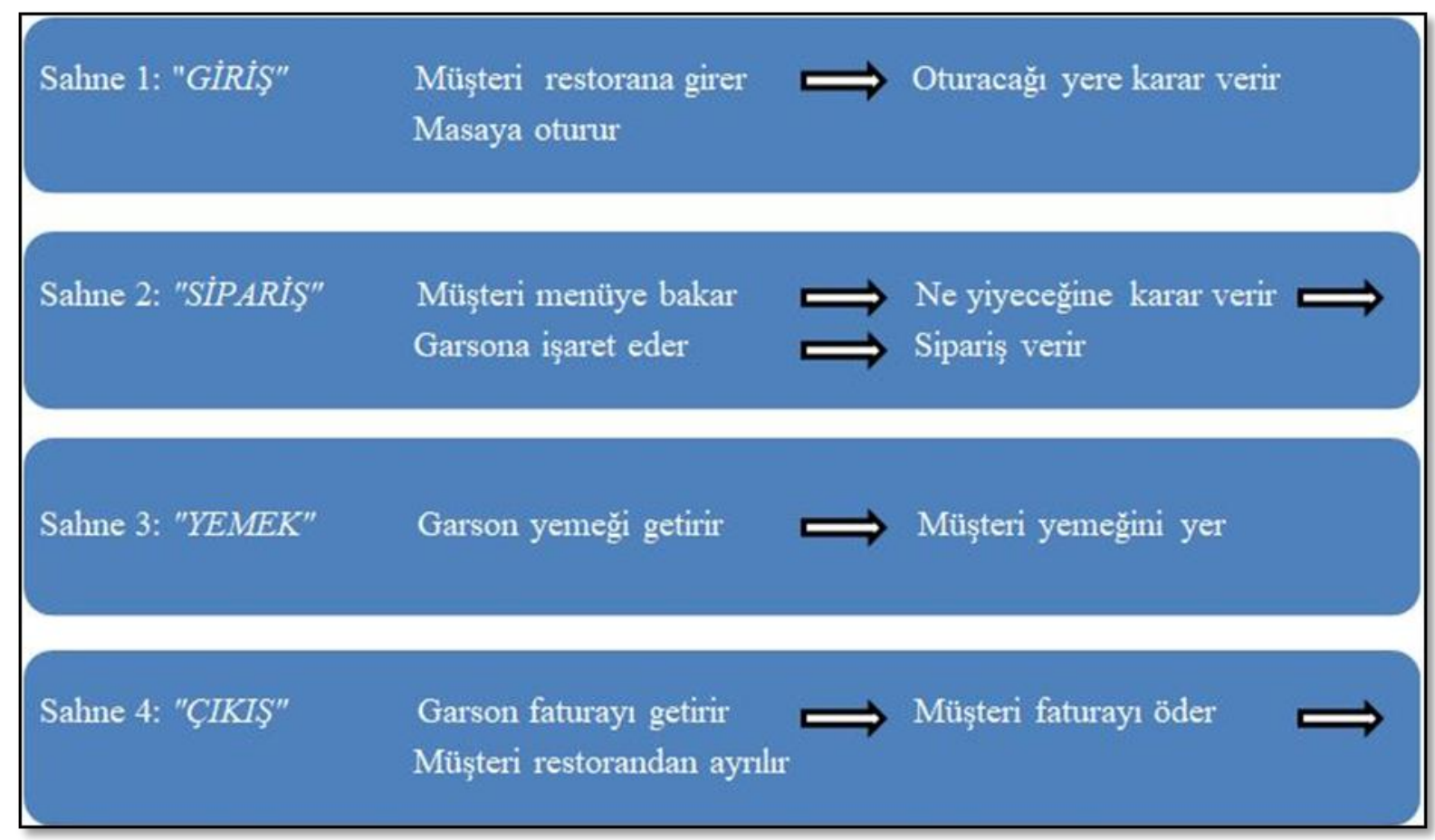

Görsel 2: Restoran Senaryosu (Bower, Black ve Turner, 1979, s. 179) (Yeniden Çizilerek)

Bir restoranda yapılacakları bilmek, "sahne 1: giriş", "sahne 2: sipariş", "sahne 3: yemek" ve "sahne 4: çıkış" gibi bir dizi olayları hatırlamak demektir. Restoranda bulunan birey, bu senaryoyu hafızadan alır ve uygular; dolayısıyla, menüye bakmak, sipariş vermek, yemek yemek ve faturayı ödemek gibi davranışlar sergilemektedir.

Biliş ve kültür ilişkisi, kültür ve mimari çevrede değişimlerin aşırı ve hızlı olduğu durumlarda daha da önem kazanmaktadır. Toplum kimliğini ortadan kaldıran, sosyal yapı, dayanışma, aidiyet duygusunu yok eden, adaptasyon sürecinde uyumu azaltan ve bilişsel şemayı bozan bu süreç aynı zamanda bireylerin yetkinliğini olumsuz yönde etkilemektedir. Biliş alanında bireylerin çevre ile ilişkilerinde yetkinliğini arttırmak amacıyla çok farklı disiplinlerde görsel ve işitsel alanlardaki çalışmalar son yıllarda önem kazanmıştır (Rapoport, 2005, Yağanoğlu ve Köse, 2018).

\section{PROBLEM ÇÖZME VE YARATICILIK}

Mimari tasarımın zaman içindeki yöntemsel değişimleri gözetildiğinde, bilişsel psikoloji konusu bir düşünce eyleminin ya da zihinsel sürecin sonucu olarak karşımıza çıkmaktadır. Bir diğer ifadeyle, kültürel davranış pratikleri ve zihinsel temsillerden yararlanarak, tasarım sürecinde problemin tanımı ve çözümü sağlanmakta ve yaratıcıllğa etki etmektedir. Problemin bellekte tanımlanması tasarımın yapılandırılması için önemli bir aşamadır. Bir problemin zihinde tasarımlanması biliş alanında önemli bir etken olup, bir tasarımın yapılandırılması için belirli problem çözme döngüsünü beraberinde getirmiştir. Problem çözümünün aşamaları;

- Problemin tespiti ve tanımlanması: Problemin varlığını belirlemek

- Problemin tanımı ve temsili: Sorunu tanımlamak ve somut durumlar (eskiz, denklem, sembol, resim vb.) aracilığılla ifade etmek

- Uygun bir strateji seçmek: Probleme dayalı strateji ya da metot (deneme-yanılma, analoji, karş1laştırma) kullanmak

- Verilerin düzenlenmesi: Toplanan verilerin organizasyonunu yapmak

- Kaynak ayırma: Zaman, para ve ekipman sağlamak

- Değerlendirme: Çalışmanın analiz süreci 
olarak siralanmaktadır.

"Bilgi depolama" başlığında ifade edildiği üzere bilişsel psikoloji konusu bilgi edinme, saklama ve kullanma (geri çağırma) aşamaları üzerinden ele alınmakta ve tasarım sürecine olan etkileri görsel malzemeler üzerinden sunulmaktadır. Diğer taraftan tasarım süreci, mevcut durumdan (hedef surum) istenen duruma (hedef durum) doğru bir akış göstermekte ve seçilen yöntemler aracillğıyla problem çözümü gerçekleşmektedir (Görsel 3). Bu açıdan bakıldığında, biliş ve yaratıcılık ilişkisindeki bir diğer önemli durumun problemin bileşenleri olduğu görülmektedir:

- Başlangıç durumu

- Operatörler (uygulanan stratejiler / metotlar)

- Engeller (yaşadığımız sınırlamalar)

- Hedef durum

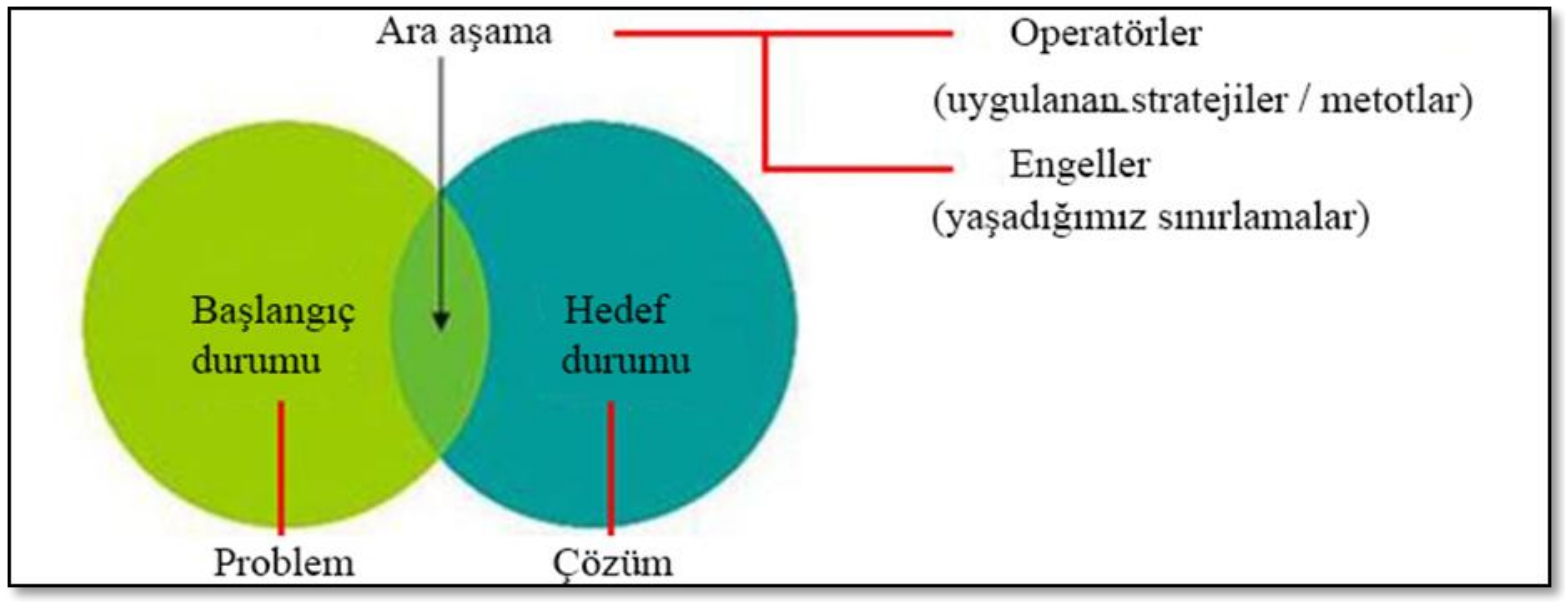

Görsel 3: Problem bileşenleri

Örneğin, bir prototip üretebilmek için, ilk aşama olarak fonksiyonun (çalışma, dinlenme, depolama, bekleme alanı vb.) analiz edilmesi gerekmektedir. Bu adımın ardından prototipin üretileceği metot belirlenmekte buna bağlı olarak, eskiz, uygulama yöntemleri vb. seçenekler seçilmektedir. $\mathrm{Bu}$ aşamada, belirli sınırlamalarla (zaman, araştırma yapmak, maliyet vb.) karşılaşılabilir. Tüm adımların ardından mekan problemine yönelik prototip tasarlanmakta ve hedef çözüme ulaşılmaktadır.

\section{KÜLTÜREL KODLAR}

Bir kavramın oluşması, zaman içerisinde toplum tarafindan varlık ya da nesnelerin kodlanmasıyla mümkündür. Fiske (2014, s. 122) bu durumu, toplumun ya da kültürün gereksinimlerini karş1lamak için geliştirilen kodları ya da bu kodların iletilmesi için var olan iletişim kanallarını işletmek için başvurulan yolları ortaya koymak şeklide açıklamaktadır; dolayısıyla kodlar, kültür kavramının anlamlandırma ve yorumlama sürecinde önemli bir rol oynamaktadır.

Kültür en genel tanımı ile insanların yaşamları boyunca elde ettikleri bilgiler, davranış ve değerler gibi ortak etmenlerin kuşaktan kuşağa aktarılmasıdır; bu bağlamda, aynı kültüre ait insanların sahip olduğu ortak değerler benzer şekilde düşünülen ve algılanan kültürel kodları meydana getirmektedir. Özellikle, coğrafyaya bağlı olarak kültürün ve kültürlerarası çeşitliliğe bağlı olarak bilişin farklılık göstermesi, kültür ve biliş arasındaki etkileşimin araştırmacılar tarafından incelenmesine neden olmaktadır. Örneğin, Edward Sapir ve Benjamin Whorf tarafından öne sürülen Sapir-Whorf hipotezine göre, bir kültürdeki dilin doğası insanların düşüncelerini etkilemektedir (Goldstein, 2013, s. 542). Whorf (1956, s. 140), Hopi Kızılderelileri'nin zaman anlayışını kültürel davranış pratikleri çerçevesinde incelemiştir; bu kapsamda, Hopi halkının zamanı açıklayan fiil çekimlerini kullanmadıklarını tespit etmiştir.

Duyguları, düşüncüleri ve deneyimleri ifade eden dil, iletişimin önemli bir dizgesidir. Kültür bileşenin en önemli parçası olarak kabul edilen dil, temelde kavramın nasıl olduğu ile ilgilenmek yerine 
kavramın zihnimizde gerçekleştiği eyleme odaklanır (Saussure, 2001). Dilin yapısını bilişsel anlamda incelediğimizde, bireyin dünya görüşü ve bilişine dair birtakım bilgilere ulaşmamız mümkündür (Görsel 4). Latin alfabesi kullanan kişiler, bakış yönüne göre Görsel 4a'yı soldan sağa doğru okumaya başlamaktadırlar; çünkü kırmızı çizgiden hareket ederek çizgisel bir okuma yaparlar ve açık bir yol oluşturmaktadırlar (Erkman Akerson, 2005, s. 238). Ancak bu durumlar, Arap alfabesi kullananlar için geçerli değildir; çünkü sağdan okumaya başlayan birey Görsel 4a'da açık bir yol olduğunu algılayamamaktadır (Erkman Akerson, 2005, s. 238-239). Benzer şekilde, Nuh'un gemisini tasvir eden Görsel 4b'de, bakış açımıza göre sağdan sola doğru ilerlemektedir; ancak, Nuh'un gemisini çizen ressamın sağdan sola doğru bir okuma alışkanlığı olduğunu düşünürsek, Latin alfabesi kullanan kişiler için ters bir durum oluşturmaktadır (Erkman Akerson, 2005, s. 238-239).

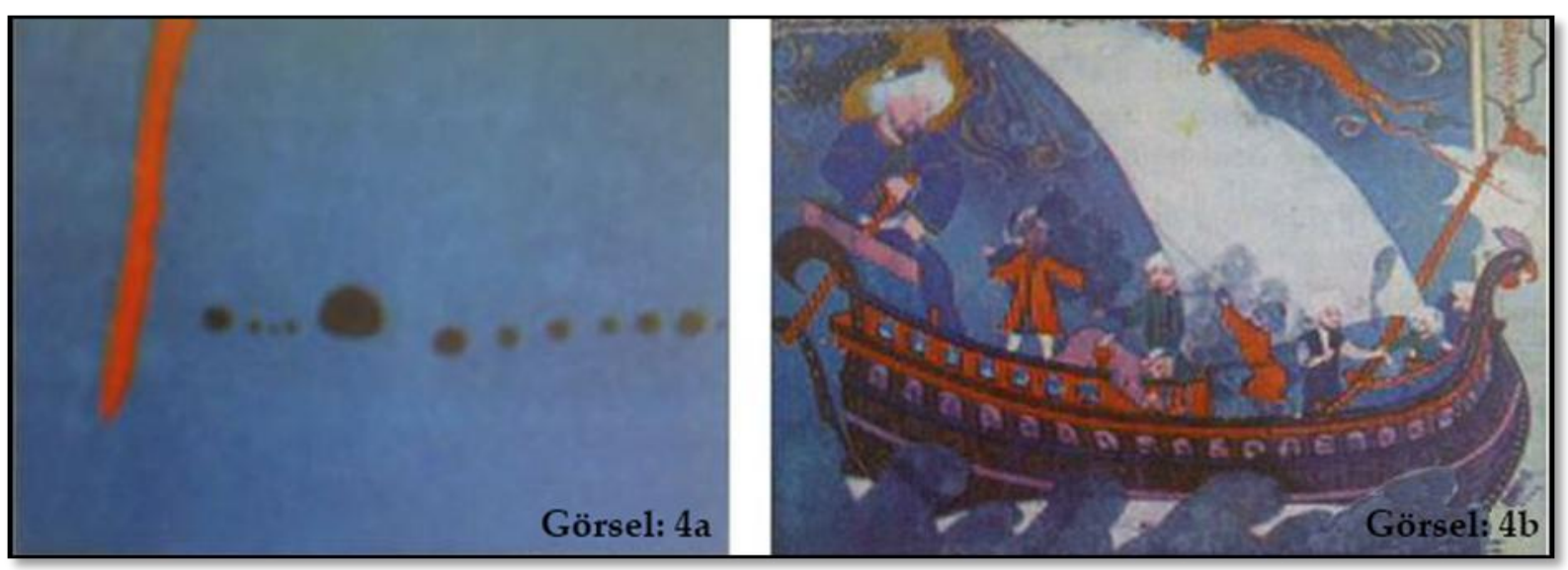

Görsel 4: Dilin yapısına bağlı olarak bilişsel anlamda görüntülerin okunması (Erkman Akerson, 2005, s. 225, 237)

Konuya ilişkin olarak "kamusal” ve "özel” kavram ikilisinin etimolojisi de örnek gösterilebilir. Bu kavram ikilisinin farklı kültür coğrafyalarında aynı şekilde var olmadığı söz konusudur. 19. Yüzyılda yayımlanan Fransızca ve İngilizce sözlüklerde "public" ve "private", "publique" ve "prive" terimleri, Osmanlıcanın kavram dünyasında tam karşılığını bulamaması, bunun yerine söz konusu kavramları karşılamak üzere bir takım önerilerde bulunularak tanımlanmaya çalışılmıştır. Dönemin entelektüel kesimi tarafından yaşadıkları kültür coğrafyasının ürettiği "mahremiyet kodları" çerçevesinde eş olmamasına rağmen, benzer bir anlama denk gelebilecek şekilde karşıllk bulunmaya çalışılmıştır (Fındıklı, 2016, s. 103).

Konuya başka bir perspektiften baktığımızda, Chiu (1972, s. 236) tarafından kültürel kodlar üzerine gerçekleştirilen bir araştırmada, Çin ve Amerikan kültürü arasındaki temel farklılıklar üzerinde durulmakta ve her iki kültüre ait özellikleri maddeler halinde karşılaştırılmaktadır:

- Çinli ebeveynler aile içindeki karşı1ıklı bağlara önem verirken, Amerikalı ebeveynler gençleri bağımsız olmaya teşvik eder.

- Çinli çocuklar dünyayı ilişki kurarak öğrenirken, Amerikalı çocukar bireysel tutum gösterir.

- Çinliler daha gelenekselcidir ve her zaman atalarının gölgesinde yaşarlar.

- Çinliler çevrelerine oldukça duyarlı iken, Amerikalılar çevrenin kendisine uymasını beklerler.

- Çinlilerin düşünme biçimi somut iken, Amerikalıların düşünce tarzı soyut ve hayalcidir.

$\mathrm{Bu}$ verilerden yola çıkarak, Çinli çocukların dış çevre ile olan ilişkisinin pasif olması, dünyayı bir ilişki ağı içerisinde incelemesini çocuk yaşta öğrenmesi önemli bir etkendir. Amerikalı çocukların soyut bir düşünce tarzını benimsemesi çıkarımsal ve hayal gücünü doğrudan etkilemiştir (Chiu, 1972, s. 240-241).

Dolayısıyla, farklı toplumlara ait kültürel kodlar, birbirinden ayrı düşünce ve davranış biçimleri sunmaktadır; buna bağlı olarak, ortaya çıkan faklı düşünme eylemi birbirinden ayrı tasarım sürecini ortaya çıkarmaktadır. Yaratıcılık ve tasarım ilişkisi zihinsel bir işlem olması sebebiyle biçim, doku, 
renk, algı vb. etmenler bakımından, farklı toplumların üretmiş olduğu mimari ürünler çeşitlilik göstermektedir.

\section{KÜLTÜREL ŞEMALAR VE MIMMARİ TASARIM ETKİLEŞİMI}

Kültürel şemalar, her tasarımcı için farklı ürünler ortaya koymayı sağlamaktadır; bu sebeple, bir anlamda bireyin yaratma sürecinin temel bileşenidir. Diğer taraftan, yaratıcılık, probleme karşı geliştirilen süreç ya da zihinsel eylemleri temsil eden durumdur. Ketizmen Önal (2011), kültürel şema ve yaratıcılığ 1 bilişsel bir yaklaşımla ele almış; tasarım sürecini zihinde gerçekleşen bir durum olması sebebiyle düşünme eylemi olarak tanımlamıştır. Biçim vermek ya da üretmek zihinsel bir projedir ve tasarımcının sahip olduğu kişisel ve kültürel bileşenleri içerir (Ketizmen Önal, 2011, s. 156; DiMaggio, 1997, s. 267).

Konseptin bir parçası olan şemalar, zihnimizde olanları yansıtmanın en pratik yoludur; çünkü, bu yöntem tasarımın her alanında kullanılmaktadır. Tasarımlarını şema aracılığıyla gerçekleştiren Le Corbusier, bu duruma örnek olarak gösterilebilir (Görsel 5-6).

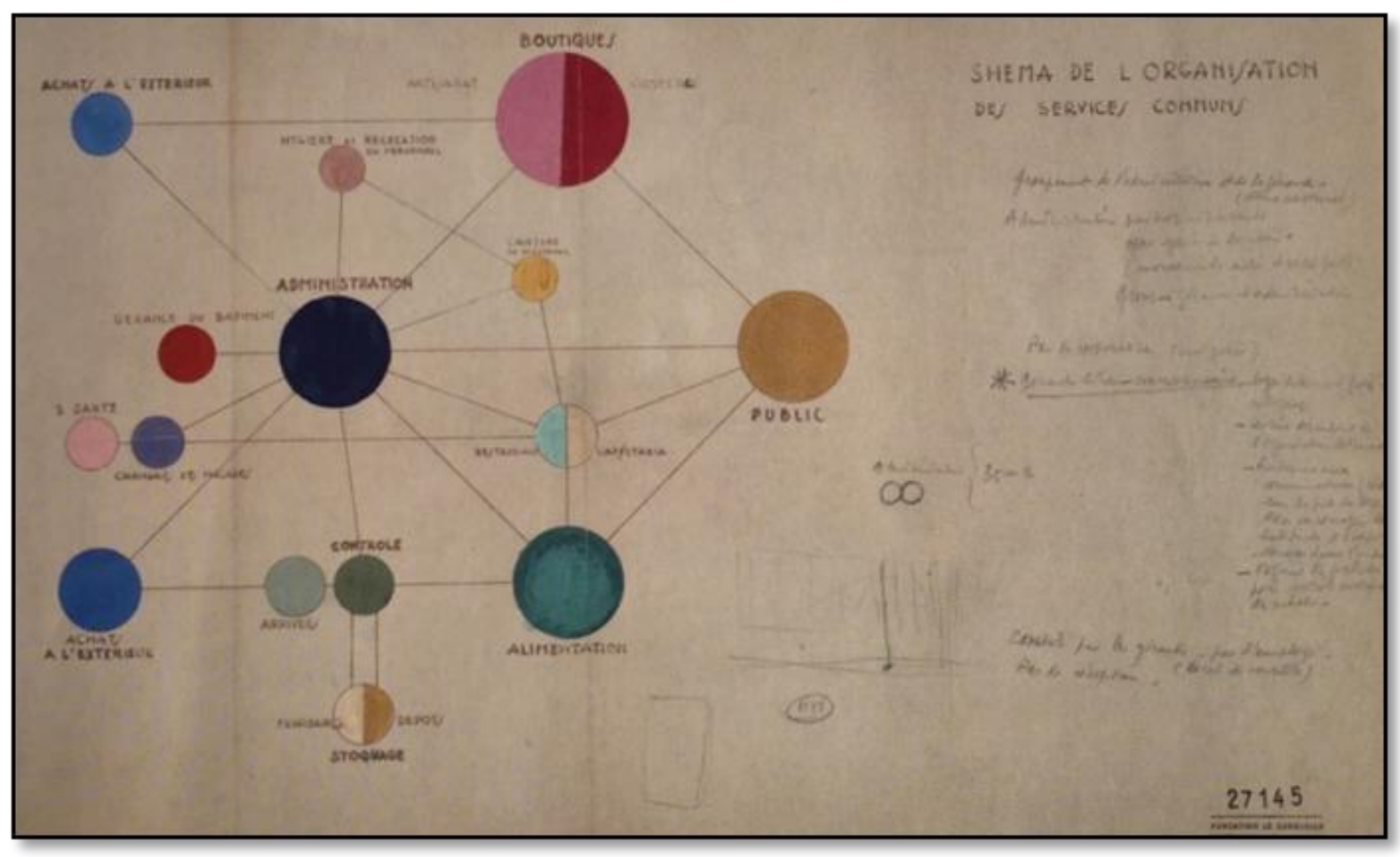

Görsel 5: Le Corbusier'in tasarımları üzerinde çalıştı̆̆ şema örneği (Garcia, 2010, s. 15)

Le Corbusier, veriler ile nasıl tasarım yapılabileceğine ilişkin yöntemi şemalar aracılığıyla kurgulamaktadır. Bu yöntem kapsamında şema ve mimari tasarım arasındaki bağlantıyı;

- sürekli olarak sorular sormak

- konsepte karar vermek

- araştırmak ve keşfetmek

- tasarımımızda nasıl deneyim kazanacağımızı anlamak

- farkli perspektiflerden bakmak

şeklinde ele almak mümkündür. 


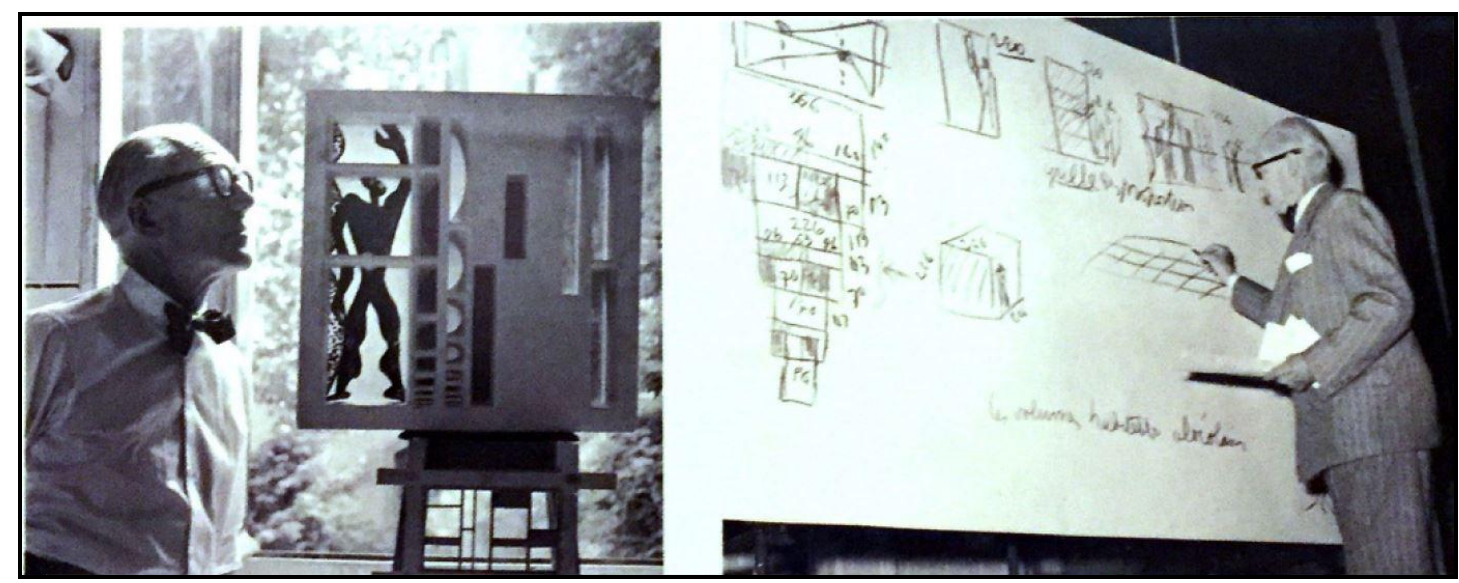

Görsel 6: Le Corbusier'in şemalar aracıllı̆ıyla gerçekleştirdiği çalışma (Garcia, 2010, s. 15)

Kültürel şemalar, bir topluma ait ortak (paylaşılan) zihinsel temsillerin bir ifadesidir (Sperber, 1996, s. 33; Shore, 1996, s. 47). Nisbett ve Norenzayan (2002, s. 6), kavramları birbirine bağlamada ve bilgiyi organize etmede yardımcı olan şemaları, kültür ile bağdaştırmaktadır; bu bağlamda, kültür insanların dünyayı kavramasını sağlayan düşünce modelleri midir? şeklinde bir soru yöneltmektedir. Bu konuyu açacak olursak, aynı kültüre ait bireylerin etkileşim halinde olduğu ya da belirli bir durum hakkında pek çok kez görüşüldüğü zaman, kültürel şemalar kişinin zihninde depolanır (Nishisa, 1999; aktaran: Ketizmen Önal: 2011, s. 159).

Kültürel şemalar, zihinsel temsiller olarak tanımlanmasına karşın, mimari tasarım ile etkileşim içindedir. Başka bir ifadeyle, herbir toplumun sahip olduğu değerler, alışkanlıklar, tutumlar, inançlar ve dünya görüşü gibi etmenler kendi içerisinde ayrılmaktadır. Bu etmenler, tasarlama bilgisinin kaynağı olarak kabul edilmektedir; çünkü, tasarım süreci bu yaratma bilgisinin kullanıldığı bilișsel bir süreçtir (Ketizmen Önal, 2011, s. 160-161). Bir kavramın oluşması, dünyanın farklı toplumları tarafindan yorumlanması ve varlık, nesne ya da durumların sinıflandırılmasına bağlıdır (Erkman Akerson, 2005, s. 45).

$\mathrm{Bu}$ ifadelerden yola çıkarak, farklı toplumlarda birbirinden bağımsız tasarım örneklerini incelemek konu bütünlüğü açısından yararlı olacaktır. Görsel 7'de gördüğümüz Selimiye Camisi, kültürel deneyimlerimizden bildiğimiz cami yapısına ait bir örnektir. Dolayısıyla, camiye ilişkin bu örnek zihnimizde uyanan ilk görüntüdür.

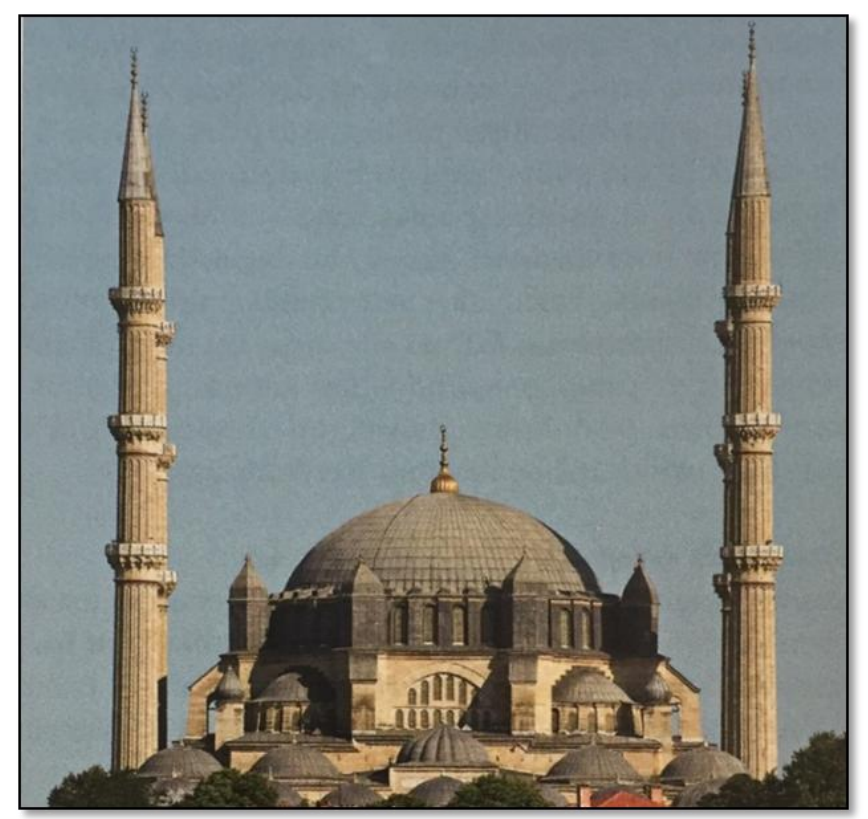

Görsel 7: Selimiye Cami örneği (Kuban 2016, s. 457). 
Görsel 8'de ise, aynı örneğin Çin ve Mali'deki temsilleri görülmektedir. Başka toplumlarda bulunan camiler kendi yorumlamalarına göre tasarlanmıştır; dolayısıyla bizim için çok şaşırtıcı ve yabancı olan bu örnekler, başka toplumlar için cami olarak nitelendirilmektedir (Erkman Akerson, 2005, s. 44-45). Çin'deki yapıya baktığımızda, kendi değerlerine ve inançlarına göre depoladıkları kültürel sistem, dini yapıları "tapınak" biçiminde ele almalarına neden olmaktadır. Benzer şekilde, Mali Timbuktu'da görülen örnekte bizim için cami yapısına uymamakta olup, coğrafyaya bağlı olarak kerpiçten yapılan özellik taşıması olarak karşımıza çıkmaktadır. Özetle, mimari tasarım bir toplum tarafından nasıl yorumlandığına ve nasıl kategorize edildiğine bağlıdır.

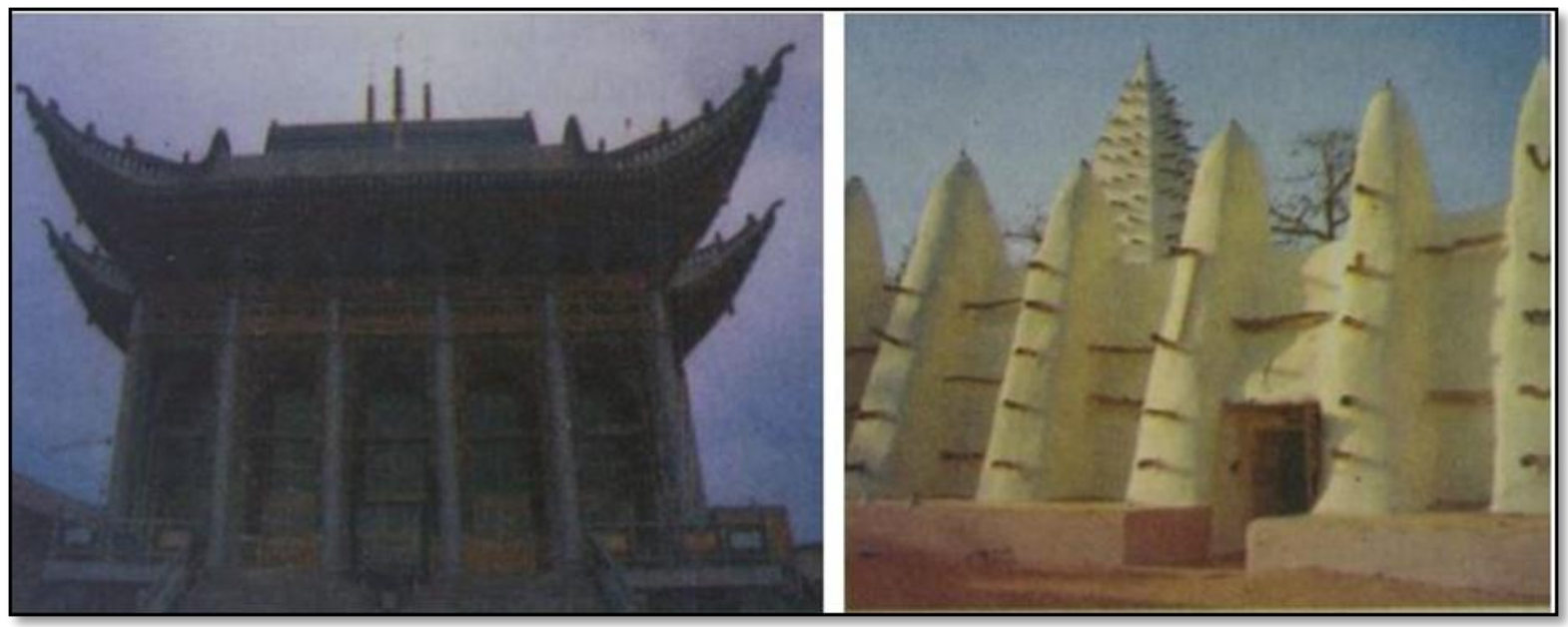

Görsel 8: Çin'de bulunan Camii örneği (Erkman Akerson, 2005, s. 44-45)

Konuya TUA Vadisi Bilgilendirme Merkezi örneği üzerinden baktığımızda, kültürel kodların geçmişe yönelik göndermeler yoluyla yapıldığına tanıklık ederiz (Görsel 9). Portekiz'de Tua vadisi üzerinde bulunan bu yapı 1880'de tren garı olarak hizmet vermektedir; ancak, günümüzde ziyaretçilerin vadinin tarihi hakkında bilgi edinmeleri amacıyla bir kültür merkezi olarak kullanılmaktadır (Arkitera, 2018). $\mathrm{Bu}$ çerçevede, geçmişe yapılan gönderme demiryolu ve tünel üzerinden kurgulanmakta adeta dış etki yapının içerisinde devam etmektedir. Geçmiş ve günümüz arasındaki söz konusu tasarım varyasyonları bir dil birliğine varmakta ve mekâna özgün bir kimlik kazandırılmaktadır.
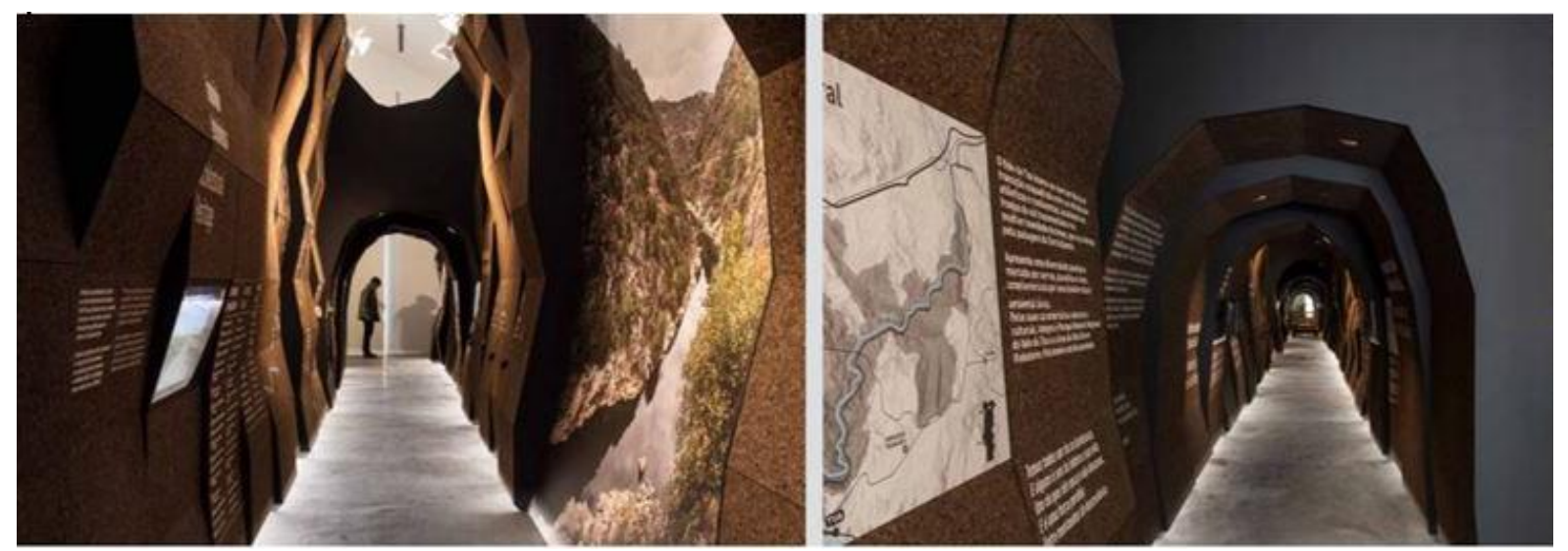

Görsel 9: TUA Bilgilendirme Merkezi (Arkitera, 2018)

Yahudi Müzesi örneğinde ise, mimari kullanılarak bir kültüre ait duyguların ziyaretçilere yansıtılması amaçlanmıştır (Görsel 10). Örneğin, binanın zikzak planı kaybolma hissini uyandırmakta, yer altında oluşturulan üç farklı rota saklanma ve yolunu kaybetme duygunu hissettirmekte ve küçük bir çizgi halindeki aydınlatmanın kullanılması İkinci Dünya Savaşı sırasında bir kültürün içinde barındırdığı umuda gönderme yapmaktadır (Arkitera, 2013). Mekânın karanlık atmosferi, bir kültürün sahip olduğu farklı deneyimlerin mimari etkileşimle yansıtabilmesine olanak vermektedir. 

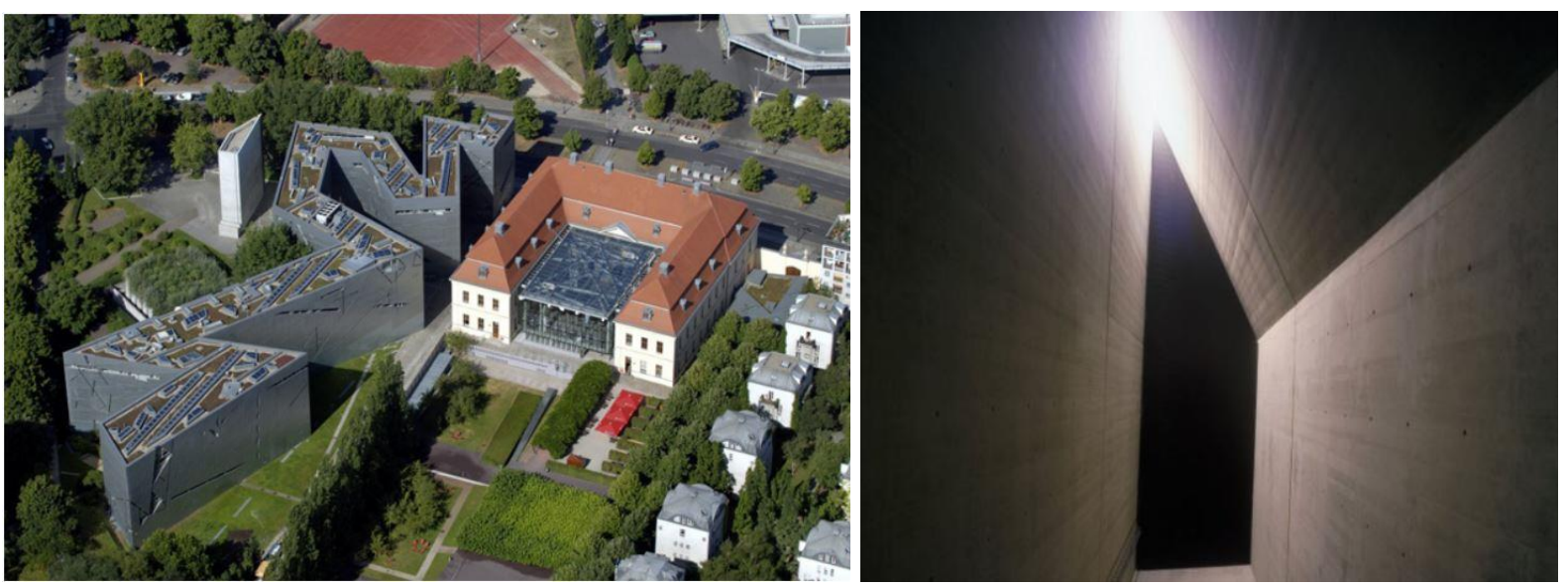

Görsel 10: Yahudi Müzesi (Arkitera, 2013)

Özetle, mimari bir tasarımı yorumlayabilmek için biçimlerin anlamlandırılması gerekmektedir. Tasarım sürecini anlamlandırmak görsel bileşenler üzerinden gerçekleşmektedir; dolayısıyla, bu durum görsel bileşenleri okuyarak verilmek istenen mesajın zihinde canlandırılmasıyla mümkündür. Her toplumun süregelen davranış ve tutumları, mimari tasarım sürecini oluşturan faktörlerdir şeklinde bir çıkarım yapmak mümkündür.

\section{SONUÇ}

Bu çalışmada, mimari tasarım süreci, bilişsel bir bakış açısıyla ele alınmıştır. Çalışma kapsamında, bir topluma ait ortak zihinsel temsillerin, deneyim yoluyla biçimlenen bir davranış halini aldığı görülmüştür. Bir topluma ait bireysel ve kültürel bilgilerin, zaman içerisinde kodlanarak tasarlama eylemine olan etkisi, kültürel şemalar çerçevesinde değerlendirilmiştir. Mimari eserler incelendiğinde, bireyin dünya görüşüne ve bilişine dair çeşitli çıarımların yapılabileceği görülmüştür; bu durum, anlam ve kavramların her toplumda farklı şekilde yorumlanmasına ve kodlanmasına neden olmuştur.

Araştırma kapsamında problem çözümünün önemi ve geliştirilmesine yönelik etmenler üzerinde de durulmuştur; bu çerçevede, sorunları keşfetmek ve tanımlamak için uygun stratejilere odaklanmak gerektiğine değinilmiştir. Bilişsel yükü en aza indirmek amacıyla, şemalar, diyagram vb. gösterimlerin kullanıldığına dikkat çekilmiştir.

Öte yandan, kültürel şemaların tasarım sürecine olan etkisini anlaşılır kılmak için, bilişsel anlamda dilin yapısına kısaca değinilmiştir. Bu süreçte, dilin yapısını biliş ve kültür arasındaki ilişki kapsamında incelediğimizde, çeşitli toplumlar tarafından farklı şekilde yorumlanan bazı örneklerle karşılaşılmıştır. Kültür nesneleri ve kültürel şemalar arasındaki sürekli etkileşim üzerinde durularak, kodların algımızı ne şekilde değiştirdiği ve kavramsal üretimi çeşitlendirmesine yönelik etkileri analiz edilmiştir. Bu doğrultuda, tasarım süreçlerinde analiz edilen ilk adım, çoğunlukla verilerin toplanması olarak belirlenmiştir. Bu verileri, gerek dışarıdan alınan görsel, işitsel ve sözel bilgiler, gerekse çağrışımlar ile uzun süreli bellekten geri çağırılan kişisel deneyimler ve gözlemler olarak ile açıklamak mümkündür (Goldstein, 2013, s. 258). Dolayısıyla, bireysel ve kültürel bilgilerin bir araya gelerek bilişi etkilemesi önemli bir etmen olarak karşımıza çıkarken, yaratıcılık ve tasarım sürecine olan yansıması birbirlerini karşılıklı olarak etkilemektedir.

Çalışmada bilişsel çözümlemeyi anlaşılır kılmak için, kavram şeklinde tanımlanan kavramlara değinilmiştir. $\mathrm{Bu}$ doğrultuda, tasarımın bir iletişim aracı olarak kullanıldığını göstermek amacıyla, mimari elemanlar sahip oldukları kodlar aracılığıyla incelenmiştir. Bu durum, mekân ve iletişimin göstergebilim kapsamında yerini ön plana çıkartmaktadır.

Sonuç olarak çalışmada, tasarım süreci ile zihin işleyişi arasındaki etkileşim bilişsel bir yaklaşımla incelenmiş̧ir. Aynı zamanda, kültürel bilginin biliş ve yaratıcılığa dair etkileri üzerinde durularak, mimari tasarımdaki yeri yeniden yorumlanmışırır. 
Bilgilendirme / Acknowledgement: Bu makale, International Conferences on Science and Technology (ICONST-EST2019) adlı konferansta 26-30 Ağustos 2019 tarihinde Kosova-Prizren'de sunulan bildiriden (Iconst Özel Say1) üretilmiştir.

\section{KAYNAKÇA}

Augoustinos, M. and Walker, I. (1995). Social cognition: An integrated introduction. Thousand Oaks, CA, US: Sage Publications, Inc.

Arkitera. (2013). Yarışmayla yapılan Yahudi müzesi. 11 Temmuz 2019 tarihinde https://www.arkitera.com/haber/yarismayla-yapilan-yahudi-muzesi/ adresinden erişildi.

Arkitera. (2018). Tua Vadisi bilgilendirme merkezi. 8 Haziran 2019 tarihinde https://www.arkitera.com/proje/tua-vadisi-bilgilendirme-merkezi/ adresinden erişildi.

Bower, G., Black, J., ve Turner, T. (1979). Scripts in memory for text. Cognitive Psychology, 11, 177-220.

Bruning, R., Schraw, G., Norby, M. and Ronning, R. (2004). Cognitive psychology and instruction (4th ed.) Upper Saddle River, New Jersey: Pearson Education Inc.

Chiu, L. H. (1972). A Cross-cultural comparison of cognitive styles in Chinese and American children. International Journal of Psychology, 7(4), 235-242.

D’Andrade, R. G. (1992). Schemas and motivation. In Roy D'Andrade and Claudia Strauss (Eds.), Human motives and cultural models. New York: Cambridge University Press.

DiMaggio, P. (1997). Culture and cognition. Annual Review of Sociology, 23, 263-287.

Erkman Akerson, F. (2005). Göstergebilime giriş. İstanbul: Multilingual.

Fındıklı, E. (2016). Uğur Tanyeli'nin mimarlık tarihiyazımında barınma kültürünün, özel ve kamusal alanın jeneolojisi. Uluslararası Tarih ve Sosyal Araştırmaları Dergisi (15), 95-128.

Fiske, John. (2014). İletişim çalışmalarına giriş. (3. Basım). (Çev. Süleyman İrvan). Ankara: Pharmakon Yayınevi.

Garcia, M. (2010). The diagrams of architecture. UK: John Wiley \& Sons Ltd.

Goldstein, E. (2013). Bilişsel psikoloji. (Çev. O. Gündüz) İstanbul: Kaknüs Yayınları.

Ketizmen Önal, G. (2011). Yaratıc1lık ve kültürel bağlamda mimari tasarım süreci. Uludăg Üniversitesi Mühendislik Mimarlık Fakültesi Dergisi, 16(1), 155-162.

Kuban, D. (2016). Osmanlı mimarisi. (2. Bask1). İstanbul: Yap1-Endüstri Merkezi Yayınlar1.

McVee, M., Dunsmore, K., and Gavelek, J. (2005). Schema theory revisited. Review of Educational Research, 75(4), 531-566.

Nisbett, R. E. and Norenzayan, A. (2002). Culture and cognition, In D. L. Medin (Ed.), Stevens' handbook of experimental psychology, (3rh ed.), New York: John Wiley \& Sons, Inc.

Rapoport, A. (2005). Culture, architecture and design. Chicago: Locke Science Pub. Co.

Saussure F. (2001). Genel dilbilim dersleri. (Çev. Berke Vardar) İstanbul: Multilingual.

Shore, B. (1996). Culture in mind: Cognition, culture and the problem of meaning. New York: Oxford University Press.

Sperber, D. (1996). Explaining culture: A naturalistic approach. Oxford: Blackwell.

Sternberg, R. J. (1996). Cognitive psychology. Orlando: FL, US: Harcout Brace College Publishers. 
Whorf, B. L. (1956). The relation of habitual thought and behavior to language. In J.B. Caroll (Ed.), Language, thought and reality: Selected writings of B. L. Whorf (s. 134-159). Cambridge, MA: MIT Press.

Yağanoğlu, M. ve Köse, C. (2018). Real-time parental voice recognition system for persons having 1mpaired hearing. Bilge International Journal of Science and Technology Research, 2(1), 4046. 